\title{
System of Sustainability Indicators Applied in River Basin Management
}

Ba talhã o, A.C.S. ${ }^{1}$, Teixeira, D. ${ }^{1}$

'Post-Graduate Prograns in Environmental and Sa nitary Engineering and Environmental Sciences - PPEAS- CIAMB, Fed eral University of G oiás - UFG.

Corresponding author: andre.ciamb.ufg@gmail.com

\section{Abstract}

The historic al context of the ind ic a tors clearly shows their complementary role in the decision-making processes, seeking to make perceptible a current condition resulting from a historical process of past practices and actions, reflecting the reflexes of previous planning. This tool can be used for river basin planning and management, including monitoring, assessment and reporting. The general a im of this research is to suggest a model of sustaina bility indic a tors for the PCJ basin committees management, as an auxiliary tool for assessing the region's susta inability level. The research to be developed has qua ntitative and qua lita tive characteristic s, characterized as a mixed method. The Preliminary findings of this research point to the need for institutional innovations and their formalization and emancipation before public management, with the creation and performance of partic ipatory procedures prescribed in specific laws, such as in the area of water resources, where the participation of multi-stakeholders through the Watershed Committees represents a signific ant breakthrough for good govemance. It is necessary to consolidate the articulation between institutions at the municipal level so that the dimensions of susta inability are treated in a fair and proactive way, so that progress towards regional susta inable development is possible.

Keywords: susta ina bility ind ic a tors, river basin management, PCJ basin committees. 


\section{Introduction}

Susta ina bility supports a universa lly shared common vision of progress towards a just, sec ure and susta inable soc iety for huma nity. This concept recognizes not only the need for environmental protection but also the urgency to improve the quality of life through strategies that create socio-economic growth and address a wide range of cross-c utting issues. While there is a growing consensus that a more susta ina ble soc iety embrac es all ind ivid ua Is, opinions about what susta ina bility means and how that can be achieved are diverse (ALSHUWAIKHAT et al., 2017).

In the monitoring of regional enviro nmental and susta ina bility issues one of the main goals is to support decisionmaking processes, thus improving regional susta ina bility ma na gement and a chieving better development results. In the face of heterogeneity of methods and tools for mea suring susta ina bility, ind ic a tors a lmost a lwa ys play a fundamental role. Sustainable Indicators a re one possible way of ensuring that sustaina bility issues a re being consistently and transparently integrated into sector activities on a local, regional and national scale. Indicators provide substantial susta ina bility performance mea surement, reporting and transparency to stakeholders (RAMOS, 2009). According to Santos (2004), regard less of the objectives or the planned site, this stra tegy requires the specialization of a broad set of data that needed to be compared, overlapped and evaluated in a holistic way.

The historic al context of the ind ic a tors clearly shows their complementary role in the decision-making processes, seeking to make perceptible a current condition resulting from a historic al process of past practices and actions, reflecting the reflexes of previous planning. When an ind ic a tor is a na lyzed, its c urrent portra it is viewed from the historical perspective, sustaining the ability to project future trendsand conditions to develop ways to monitor and measure its temporal behavior (BATALHÃO; TEIXEIRA, 2017).

Susta ina bility ind ic a to rs a re essentia I tools to ensure the identific ation of a comprehensive strategiesand realistic way of a ssessing and improving sustainability. This tool can be used for river basin planning and management, including monitoring, assessment and reporting. Also, ind ic a tors are important assessment tools to id entify social needs and contribute to public planning and management. However, the properuse of indic ators in the public management is still a methodological and politic al challenge with rather vague guidelines in many scales. Few studies explored the different potential uses and impacts of indic a tors a s complementary tool to decision-making in water management and planning processes (WU; LEONG, 2016).

The development of strategies related to the monitoring of sustainable development requires data and information of va rious natures. Indic a tors fulfill this role, with qua ntita tive and qualita tive attributions, as they qua ntify and simplify complex phenomena and realities to a manageable amount of significant information to foment the dec ision-making process (HARMANCIOGLU; BARBAROS; CEINKAYA, 2013).

At regional scale, planning for the proposal of sustainable development is more comprehensive and robust, by the size of the temitory and by the number of key actors, which facilita tes the identific ation 
of problems, community demands and local knowledge, with grea ter possib ilities for partic ipation. Mic kwitz et al. (2006) emphasizes that on a regional sc a le any attempt at metho dologic al genera liza tion can be questioned because the problems are different and need customized tools.

Meet the susta ina bility development demands are critical to a renewal and ma intenance of practic es that enable an effective and secure flow of information to strengthen the most important decision-making processes. From the management of water and the environment we can perceive multiple relationships and interactions and their regional interests. Therefore, it is nec essary to promote a ssessments and work with findings to project trends. This is justified by the increasing demand for evalua tion systems using ind ic a tors that capture the subjectivities of the research object and make them objective.

In this perspective, this study c an also assist river basin committees and public management, serving as a reference for the development and maintenance of public polic iesaimed at basin susta inability, considering the use of water, its economic importa nce, environmental degradation, and the level of productivity, a mong its multiple dimensions. This contributes to broadening the vision of all the actors involved in the management of the basins and the municipalities that constitute these spaces, generating new discussions about the factors that may enable a way to promote development, not forgetting the social and environmental demands, leaving behind the concept that development is only chained to economic growth. Scientifically, its relevance is in the development and reproducibility of the methodology, considering possible adaptations to the regions of a nalysis, and can serve as a starting point for future work.

For this, the research's main issue should answer the question:

- Is it possible to find ways to evaluate the sustainability level of Piracicaba, Capivari and J undiaí (PCJ) basin region in Brazil using the Basin Plan as a reference and involving key stakeholders (decision makers, basin committees, organized civil society, municipal/ state/federal agencies, consultancies and other users) based on a set of indicators which considers the characteristics of susta inability and meets the wishes and demands of the stakeholders, to improve the management of the subjects related to susta inable development?

In a ddition, confirm or falsify a ma in hypothesis which is:

- It is possible to develop a model (structure) of indicators based on the participation of the key stakeholders, which can serve as an evaluation tool for the elaboration of a situational pic ture of the object, and also as a complementary tool for the management of susta inable development within the framework of PCJ basin.

The general a im of this research is to suggest a model of susta ina bility indic a tors for the PCJ basin committees the management, as an a uxiliary tool for assessing the region's susta ina bility level. In order to achieve the major goal, the research plan will be developed in five tasks that a re shortly described:

To provide an overview of the challenges and demands present in the literature and associate them with the main 
stages of elaboration and implementation of susta ina bility ind ic a tors.

- To analyze the main models of systems of indic a tors a pplied in river basins region based on initiatives of indicators in the world;

- To evaluate practices and environmental and susta ina bility management) related to municipal water resources based on selfassessment;

- To identify and involve the decision makers of the basin committees and other stakeholders in order to ensure their participation in the process of selection and development of the set of indicators based on Agenda 2030 (building the archetype);

- To apply the new methodological proposal of indicators systems developed in the previous stage, in order to evaluate the level of sustainability of the region and to visualize future scenarios.

\section{Methods}

\section{study area}

The study a rea of this research is delimited by the region of PCJ river basins, and has a n approximate area of $15,320 \mathrm{~km}^{2}$. Approximately $92 \%$ of this a rea a bout $14,040 \mathrm{~km}^{2}$ are in the State of São Paulo and the remaining $1,280 \mathrm{~km}^{2}$ belong to the State of Minas Gerais, Brazil, where the headwaters of the Jaguari, Camanducaia and Atibaia rivers are loc ated. This a rea is located between the meridians 460 and 49o west and the la titudes $22 \circ$ and $23.5 \circ$ so uth, presenting an approximate extension of $300 \mathrm{~km}$, in the east-west direction, and of $100 \mathrm{~km}$, in the north-so uth direction (AGENCIA DAS BACIAS PCJ , 2016).

The region of $\mathrm{PCJ}$ river basinscovers a reas of 76 munic ipalities, and 62 are headquartered in the region's drainage areas. Of these, 58 are in the State of São Paulo and four in Minas Gera is. With approxima tely five million inhabitants, this region is considered one of the most important in Brazil due to its economic development, which represents about 7\% of the National Gross Domestic Product (GDP). The munic ipalities of the State of São Paulo with headquarters in the region belong to Campinas, which also includes municipalities located in the Alto Mogi-Guaçu basin. In the PCJ basins there are five Govemment regions of Sã o Paulo's Sta te: Ca mpina s region, J undiaí region, Piracicaba region, Limeira region and Bragança Paulista region, which are intermediate levels of politic al-a d ministra tive management between the Administrative Region and munic ipalities. (PCJ , 2016).

The main justification for choosing the hydrographic basins of the Piracic aba, Capiva ri and J undiaí rivers for resea rch is the emerging need to communic ate (information system) the society and the main stakeholders about the levels of development and sustainability of these basins, which has great economic and strategic importance for the Sta te of São Paulo, Brazil, in order to evaluate the environmental, economic, social and institutional spheres seeking the understanding of the susta inable soc iety- environment relationship. 
System of Sustainabil ty Indicators Appl ed...

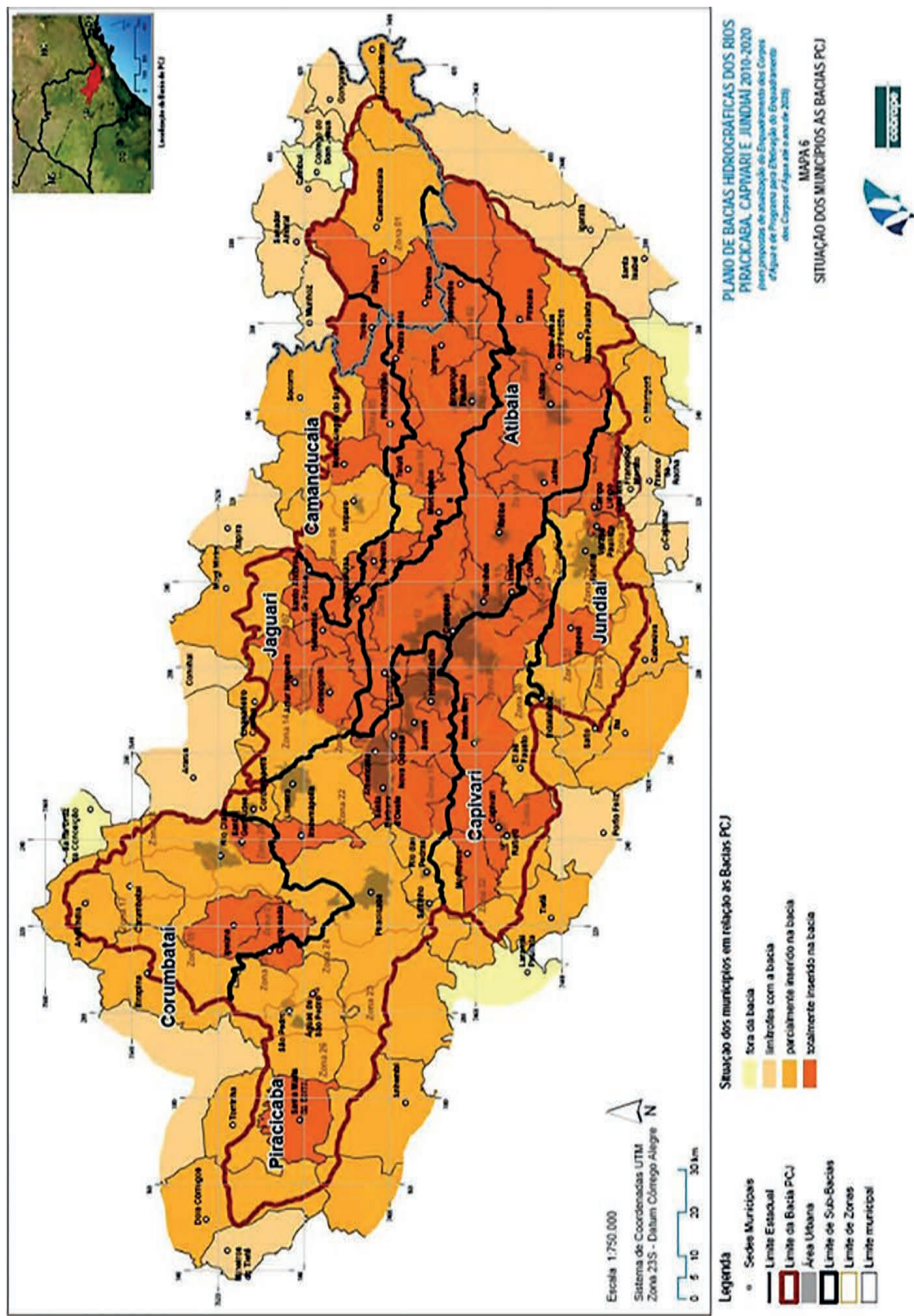

Figure 1 - Spatial location of the object of study. Source: Agência das Bacias PCJ, 2016. 


\section{Methodo 7 ogica 7 resources}

The research to be developed has qua ntita tive and qua lita tive cha rac teristics, characterized as a mixed method. The quantitative part will be based on a structured procedure for the collection of secondary data, sought in reference sources already used in the Basin Plan, and other sources that a re in line with the resea rch objectives. Already, in the qualita tive part will be used the semi-structured questionna ire instruments and individual and collective interviews, personally and electronically, with the participants chosen for the research, representing a focus group. In this case, the scope of potentially relevant info mation provided by the interviewee is restricted, where the interview guide has a directive function. Mixed methods allow better exploration and explanation of data and information, and are an opportunity to develop new methodological skills for research.

The triangulation method will be used to combine the results of qua ntitative and qualitative methods. In this case, the different methodologic al perspectives a re complemented for the a nalysis of a theme, this process being understood as the complementary compensation of the deficiencies and the obscure points of each isolated method. The basis of this view is that "qualita tive and qua ntitative methods must be seen as complementary rather than rival fields" (J ICK, 1983, p. 135). However, the various methods rema in a utonomous, continue to operate side by side, having as a meeting point the subject under study.

Figure 2 contains the methodological summary in a simplified way.

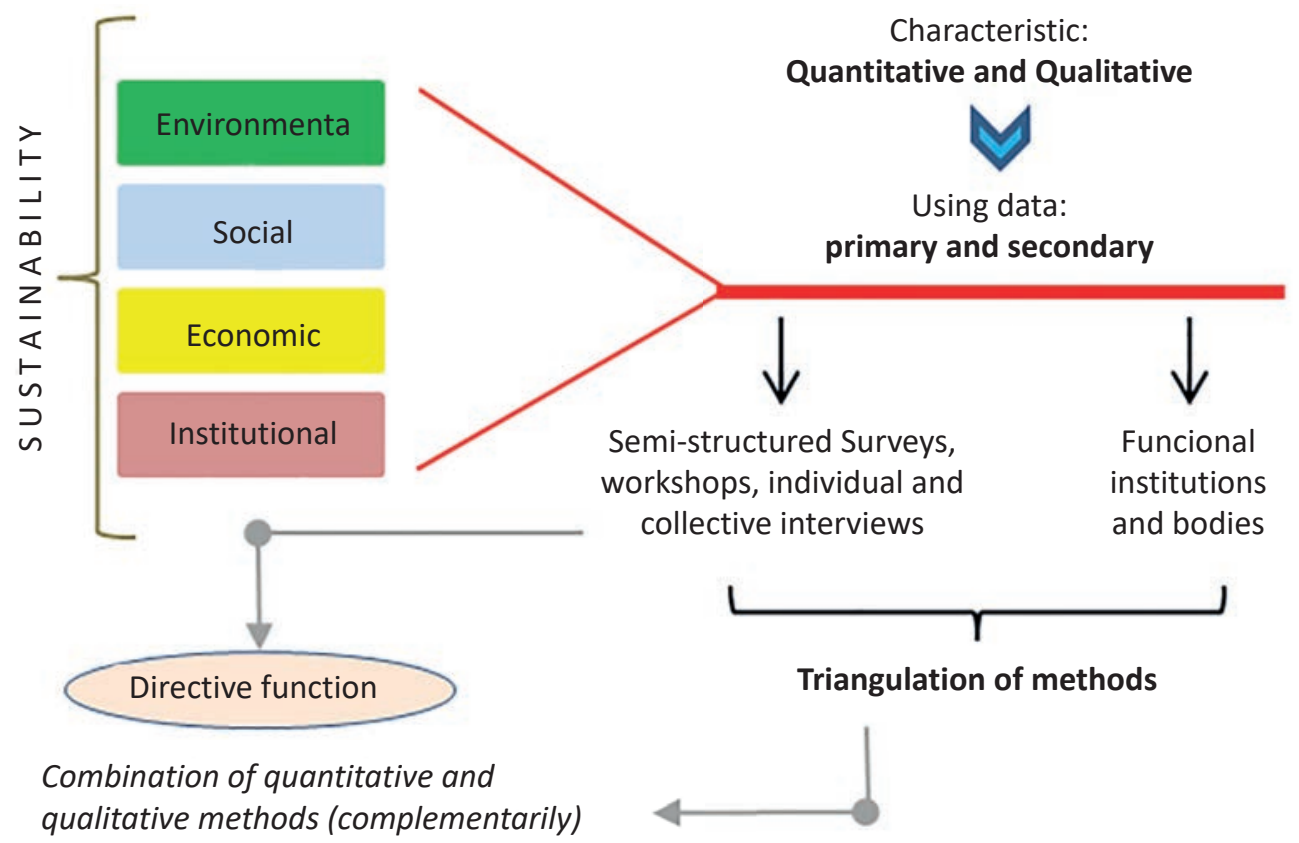

Figure 2 - Methodological summary of study. Source: Prepared by the authors. 


\section{Preliminary results}

So far we can offer some preliminary results of this research. We generate the profile of river basin initiatives in the world that use indic a tors in their experiences. These findings genera te the general profile:

- Regionalarea;
- Using pure indicators approach;

- Based on environmental scope; (it limits the evaluation of susta ina bility, and does not reflect the interactions between environment and society).

These findings may be better perceived in Figure 3.

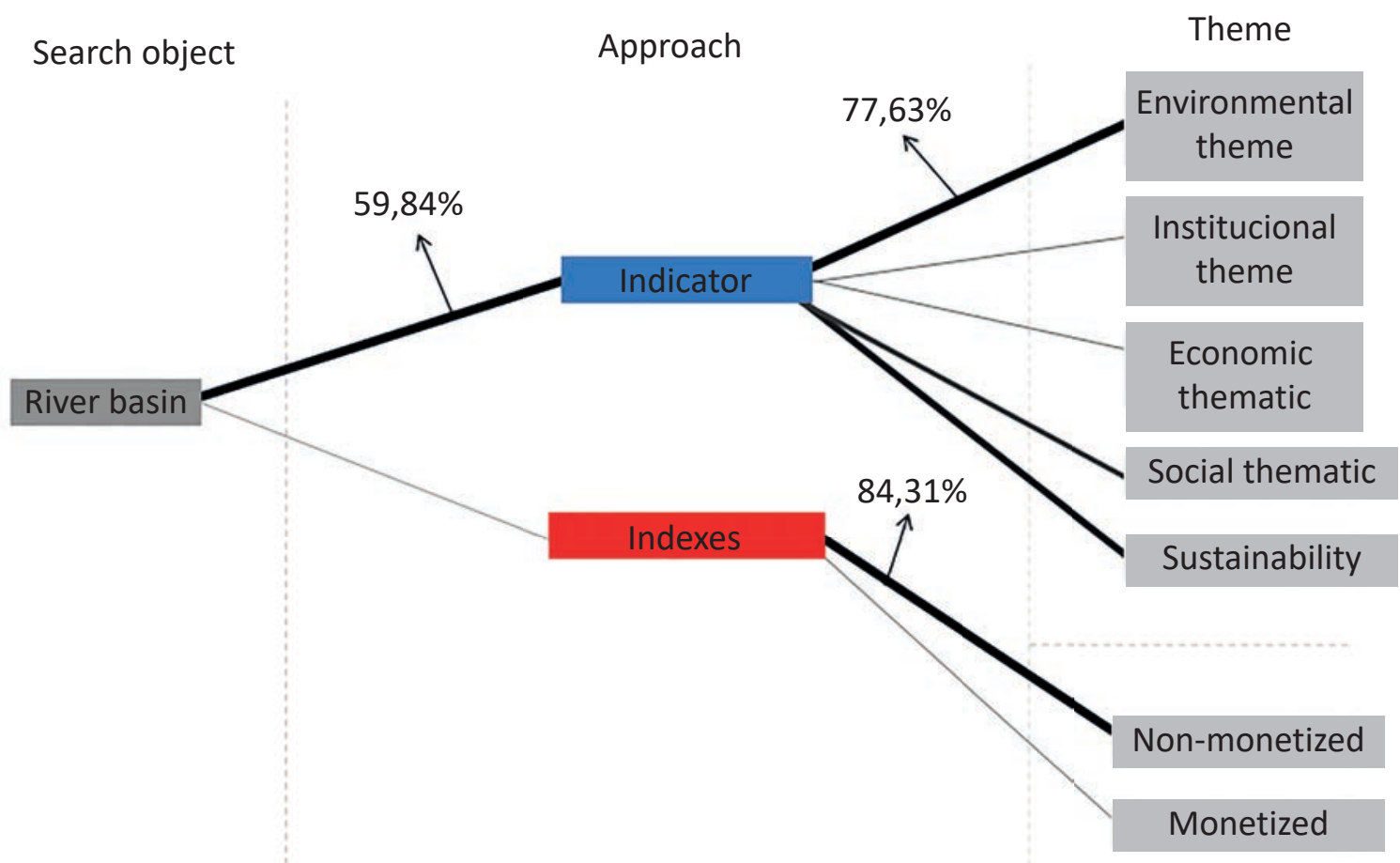

Figure 3 - Profile of river basin initiatives in the world using indicators. Source: Prepared by the authors.

In indexes the scope doesnot have a centra lity in the environmental dimension, using different dimensions (ecological, social, economic, and institutional). Here the non-monetized was greater than the monetary valuation.So far we have the following findings regarding field research:
- 76 munic ipa lities are involved in this research;

- $42 \%$ were concluded so far being $70 \%$ face-to-face visits;

- $58 \%$ of them had a high level of response (75\% - 100\%).

Figure 4 presents these preliminary field work findings. 
Municipalities covered so far $\longrightarrow 42 \% \longrightarrow 70 \%$ face-to-face visits

\begin{tabular}{|c|c|}
\hline $\begin{array}{c}\text { Distribution by size of municipality in study } \\
\text { area }\end{array}$ & Proportion \\
\hline up to 100 thousandinhabitants & $74 \%$ \\
\hline 100 thousand - 500 thousandinhabitants & $25 \%$ \\
\hline above 500 thousand inhabitants & $1 \%$ \\
\hline
\end{tabular}

\begin{tabular}{|c|c|}
\hline Responses by municipality size so far & Proportion \\
\hline up to 100 thousandinhabitants & $47 \%$ \\
\hline 100 thousand - 500 thousand inhabitants & $35 \%$ \\
\hline above 500 thousand inhabitants & $100 \%$ \\
\hline
\end{tabular}

Figure 4 - Preliminary results of fieldwork.

According to the literature of the topic studied, the level of response is considered acceptable for a nalysis of the results. However, we are still looking to improve these numbers to provide a more robust result.

There is inc rea sing recognition of one's own institutional limitations in dea ling with complex problems at all spatial scales. The findings of this research point to the need for institutional innovations a nd their forma lization and emancipation before public management, with the creation and performance of participatory procedures prescribed in specific laws, such as in the area of water resources, where the participation of multi-sta keholders through the Watershed Committees represents a signific ant breakthrough for good govemance. It is necessary to consolidate the artic ulation between institutions at the municipal level so that the dimensions of susta inability a re treated in a fair and proactive way, so that progress towards regional sustainable development is possible. The diffic ulty in this research so far is to access and streamline a link with the va rious stakeholders and to build interfaces with inter-sectora I relationships to stimula te the flow of information in these networks.

Many challenges have been found for the construction of evaluation systems with ind ic a to rs like: geogra phic al or spatial delimita tion; temporal disc ontinuity; validation; type of aggregation; lack of information; subjectivity of the concept of susta ina bility; a ccess to data; decision support/policy advisor; methodological consensus; integration of information; mea sura bility; complexity; qua lity of data; potential use; medium and long-term approach - targets; legal congruence; partic ipatory ap proach; relevance; credibility; legitima cy; tra nspa rency; technical knowledge; effective communication; compara tive a na lysis; op era tio na liza tion; selection; monitoring; self-evaluation; scope definition. 


\section{References}

AGENCIA DAS BACIAS PCJ- PIRACICABA, CAPIVARI E JUNDIAÍ. Informações das bacias PCJ. Avaiable from: http://www.agenciapcj.org.br/novo/informacoesdas-bacias>. Access: july, 2016.

ALSHUWAIKHAT, H.M., ABUBAKAR, I.R., AINA, Y.A., ADENLE, Y.A. and UMAIR, M., 2017. The Development of a GIS-Based Model for Campus Environmental Sustainability Assessment. Sustainability, vol. 9, no. 439, pp.1-23.

BATALHÃO, A.C.S. and TEIXEIRA, D., 2017. Indicators Approaches in Municipal Sustainability. Saarbrücken: Novas Edições Acadêmicas.

HARMANCIUGLU, N. B., BARBAROS, F. and CENTIKAYA, C. P., 2013. Sustainability Issues in Water Management. Water Resources Management, vol. 27, pp. 18671891.
JICK, T., 1983. Mixing Qualitative and Quantitative Methods: Triangulation in Action. IN: MAANEN, J. V. (ed.), Qualitative Methodology. London: SAGE. pp. 135-148.

MICKWITZ, P., MELANEN, M., ROSENSTROM, U. and SEPPALA, J., 2006. Regional eco-efficiency indicators - a participatory approach. Journal of Cleaner Production, vol. 14, no. 18, pp. 1603-1611.

RAMOS, T.B., 2009. Development of regional sustainability indicators and the role of academia in this process: the Portuguese Practice. Journal of Cleaner Production, vol. 17, pp. 1101-1115.

SANTOS, R.F., 2004. Planejamento Ambiental: teoria e prática. São Paulo: Oficina de Textos.

WU, H. and LEONG, C., 2016. A composite framework of river sustainability: integration across time, space and interests in the Yellow River and Ganges River. Water Policy vol. 18, pp. 138-152. 